J. Appl. Cryst. (1974). 7, 223

\title{
A Neutron Small-Angle Scattering Investigation of Voids in Neutron-Irradiated Aluminum Single Crystals*
}

\author{
By R. W. Hendricks, $\uparrow$ J. Schelten and W. Schmatz \\ Institut für Festkörperforschung der Kernforschungsanlage Jülich, Germany (BRD)
}

Large single crystals of high-purity aluminum (99.9999+\%), in the form of cylinders $25 \mathrm{~mm}$ dia $\times 40$ $\mathrm{mm}$ long, were irradiated in the removable beryllium shield of the Oak Ridge High-Flux Isotope Reactor to fluences between $5 \times 10^{20}$ and $1.5 \times 10^{21} \mathrm{n} / \mathrm{cm}^{2}(E>0.1 \mathrm{Mev})$. Six of these crystals have been examined at the neutron small-angle scattering facility at the FRJ-2 reactor in Jülich. Scattering curves have been measured in essentially a point geometry at specimen-to-detector distances of 12, 5,2, and $1 \mathrm{~m}$, which cover a K range of $2 \times 10^{-3}$ to $2 \times 10^{-1} \AA$ in overlapping steps. The scattering from the irradiated specimens is well above the scattering from the unirradiated single crystals except at the largest $\mathbf{K}$ vectors, where the intensity is principally the weak incoherent scattering from Al. Nonsymmetric scattering effects have been observed in the high-angle tails of the curves from the unirradiated specimens. Throughout, especial attention has been paid to the scattering curves in the regions of relatively high $\mathbf{K}$ where a previously small-angle $\mathbf{X}$-ray investigation has suggested that there may be some effects from voids or other scattering centers which are below the limit of resolution of the electron microscope. These data are compared with electron microscopy, small-angle X-ray scattering, and immersion density measurements. The void-size distribution function and its first three moments are computed.

* Research sponsored by the U.S. Atomic Energy Commission under contract with the Union Carbide Corporation, and by the Kernforschungsanlage Jülich $\mathrm{GmbH}$.

$\dagger$ On research assignment from Oak Ridge National Laboratory, Oak Ridge, Tennessee. 37830.

$\$$ The crystals were grown by F. W. Young and irradiated in conjunction with $\mathrm{H}$. Mook of ORNL.

J. Appl. Cryst. (1974). 7, 223

\section{Application of SAXS to the Study of Microporosity of Graphitic Materials for High-Temperature Nuclear Reactors}

\author{
By P. Krautwasser, K. Koizlik and H. Nickel \\ Kernforschungsanlage Jülich GmbH, D-517 Jülich, Germany (BRD), \\ P. Koss \\ Reaktorzentrum Seibersdorf, A-1082 Wien VIII, Austria \\ AND W. RULAND \\ Universität Marburg, 355 Marburg, Germany (BRD)
}

\begin{abstract}
Measurements of microporosity changes in graphitic materials for high-temperature reactors - pyrocarbon, graphite and matrix materials - during heat treatment and irradiation were expected to be of interest because of the following reasons: $(a)$ porosity and porc-size distribution seem to be primarily responsible for fission-product transport, $(b)$ irradiation experiments show a strong influence of density, i.e. of porosity, on the irradiation behaviour. First investigations showed the presence of a pore-size distribution in the range of about $5 \AA$ (vacancies) up to more than $5000 \AA$ diameter in all these graphitic materials. It can be assumed that there exists a large variety of pore shapes, from spherical to wedgeshaped pores. Study on pyrocarbon: The mechanical behaviour of pyrocarbon coating layers during heat treatment and irradiation is partly governed by creep processes. Creep processes are generally explained by stress-directed motion of vacancies or small clusters of vacancies which cause an increase in anisotropy. This should result in an overall change in the pore-size distribution. Therefore the first
\end{abstract}

